\title{
OS AXIOMAS DO PENSAMENTO SOCRÁTICO
}

\author{
Aldo Lopes Dinucci \\ Universidade Federal de Sergipe
}

\begin{abstract}
In this paper, we will see that Socrates bonds himself with the three basic axioms of realism: things have essence, words have sense, there is a relation between the meanings of the words and the essences of the things, supposing also that virtue is a state of the soul. These axioms form the background of the socratic thought: Socrates, seeing himself in a world where the ruling principles, steady and stable, conduct the perpetual flux of changes, goes in search of the moral arete which, being in itself steady and stable, determines the excellence of men and their actions.
\end{abstract}

Keywords: Ethics, Socrates, sSocratism, Classical Philosophy.

Resumo: Neste artigo, veremos que Sócrates se compromete com os três axiomas básicos do realismo: as coisas têm essência, as palavras têm sentido, há uma correspondência entre os sentidos das palavras e as essências das coisas, supondo também que a virtude é um estado da alma. Estes axiomas formam o pano de fundo do pensamento socrático: Sócrates, vendo a si mesmo num mundo onde os princípios reguladores, fixos e estáveis, conduzem o fluxo perpétuo das mudanças, sai à procura da arete moral que, sendo em si mesma fixa e estável, determina a excelência dos homens e de suas ações.

Palavras-chave: Ética, Sócrates, socratismo, Filosofia Clássica.

Sabemos que o elenchus de teste de definições tem como fundamento epistemológico o princípio da prioridade da definição (PD), segundo o qual "Se A não sabe o que é a definição de F, então A não pode saber nada sobre

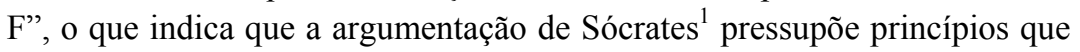

\footnotetext{
1 Este Sócrates ao qual me refiro ao longo deste artigo é o personagem Sócrates dos assim chamados primeiros diálogos de Platão (Apologia, Carmides, Criton, Eutífron, Eutideno, Górgias, Hípias Menor, Íon, Lísias, Laques, Protágoras, Livro 1 da República e primeira parte do Mênon), diálogos que conteriam o pensamento do Sócrates histórico, que se caracterizaria, entre outras coisas, por seu caráter aporético e
} 
não são nunca explicados por ele mesmo: Sócrates não se limita a propor implicitamente (PD) a seus interlocutores, mas supõe também uma concepção de virtude distante do senso comum. Examinaremos nesse artigo os seguintes pressupostos da argumentação socrática: a tese segundo a qual coisas tem uma essência (eidos) e a tese segundo a qual a virtude é sempre boa e benéfica.

Chamemos de formas ou essências (eidos) aquilo sem o que as coisas não são o que são e com o que elas são o que são. Como veremos, Sócrates utiliza uma certa noção de essência (eidos) sem definir seu status metafísico. Quanto a esta indeterminação, alguns autores buscam defender Sócrates afirmando que, de fato, Sócrates pressupunha, em sua argumentação, uma crença nas formas das coisas:

Subjazendo ao procedimento de Sócrates está um pressuposto - diz Guthrie (1969, p. 120)- ou crença nunca mencionado porque não reconhecido conscientemente, que as espécies ou classes às quais as coisas particulares pertencem, as 'formas' que elas possuem, têm uma natureza quase-substancial e [...] uma estabilidade que permite que a essência de cada coisa seja atingida, descrita e claramente distinta de todas as outras essências.

Entretanto, esta estratégia de defesa da posição socrática culmina com a afirmação de que tal noção de forma já subjazia à cultura grega, o que leva ainda à tese de que a Teoria Platônica das Formas nada é senão o ápice de um processo gradual de tomada de consciência da própria cultura grega. Sócrates, assim, nada fizera senão tomar "no ar" uma noção que já circulava implicitamente na sua cultura, cabendo a Platão aprofundar e desenvolver um aparato conceitual que tem como matriz esta noção primitiva de eidos. Nosso argumento quanto a esta tese é o seguinte: aceitamos que esta noção preexistisse como possibilidade no seio da cultura grega. Entretanto, isto não autoriza Sócrates a utilizar implicitamente tal noção como fundamento de sua argumentação quando, por exemplo, discutindo com sofistas (como Górgias) que rejeitam explicitamente qualquer noção de um ser estável que escape às coisas imersas no fluxo das mudanças. Cabe então a questão: Que

exclusivamente ético e por não conter teorias propriamente platônicas, como a tese do Mundo das Idéias, a tese da imortalidade da alma e a teoria da reminiscência. 
justificativa Sócrates oferece para supor que as coisas possuem essências e que estas são condição necessária e suficiente para o verdadeiro conhecimento destas mesmas coisas? Buscando responder a esta indagação, trataremos a seguir da concepção socrática de definição.

Sabemos que Sócrates vê como fundamental conhecer a definição da coisa para saber o que a coisa é. E, como Sócrates tem como exclusiva preocupação os temas morais, no mais das vezes o vemos diante da necessidade de buscar a definição da essência de uma ou outra virtude. Assim, por exemplo, no Carmides, Sócrates busca primeiro saber o que é temperança para assim saber se a temperança está presente no seu interlocutor (157 c $7-158$ e 5). E para saber o que é a temperança, é preciso primeiramente expressar por palavras o que é a temperança: "Se nós podemos ser bons conselheiros sobre esta questão - diz-nos Irwin (1995, p. 21 - c.f. Platão, Laques, 190 b 3- c 7)- nós devemos saber o que a virtude é: se nós sabemos o que ela é, nós podemos dizer o que ela é”. Mas primeiramente Sócrates quer saber o que o interlocutor crê ser a temperança (Laques, $158 \mathrm{e}$ 7- 159 a 10) para, a partir disto, iniciar o teste de definições.

Entretanto, que características uma definição deve possuir para ser aceita como candidata a uma verdadeira definição e, assim, participar do teste de definições? É isto o que consideraremos a seguir. Como observa Richard Robinson (1966, p. 111), a questão "O que é x?" só aparece de fato em três dos primeiros diálogos como questão primária do elenchus (no Eutífron, no Laques, no Carmides). No Górgias, no Mênon (no elenchus que abre caminho para a solução geométrica da diagonal) e no livro I da República, a questão é “x é y?”. No Íon, no Hípias Menor, na Apologia, no Criton e no Protágoras tal questão não é sequer levantada. A importância da questão "O que é X?” não se deriva, portanto, de seu número de ocorrências nos diálogos socráticos, mas da importância que Sócrates confere a ela, sobretudo do fato de ser ele muito meticuloso no que se refere às definições. Com efeito, Sócrates muitas vezes obriga o interlocutor a reformular um esboço de definição até que este seja aceita como candidato a uma verdadeira definição.

Para Sócrates, a candidata a uma verdadeira definição deve expressar a essência presente em toda e qualquer coisa detentora daquela propriedade que se quer definir (Cf. Eutífron, 5 d 1-5). Assim, a resposta satisfatória deverá ser uma definição que se aplique a todas as coisas que possuam a propriedade em questão (Irwin, 1995, p. 23), sem incluir também, naturalmente, coisas que não possuam tal propriedade (Nakhnikian, 1966, p. 127). 
A partir disto, Irwin (1995, p. 23) declara que Sócrates faz duas exigências básicas para a definição: (1) a exigência epistemológica, segundo a qual devemos conhecer a coisa pelo modo correto (i.e. pelo seu eidos) e (2) a exigência metafísica, segundo a qual devemos identificar a coisa a ser definida com o eidos pelo qual explicam-se as propriedades relevantes presentes na coisa em questão. Além disto, de acordo com (1), a definição não deve conter entre seus termos a própria coisa que ser quer definir (Cf. Eutífron, 7 b 6 - d 7) e, de acordo com (2), o eidos deve ser o último termo da série - não pode haver um outro termo ou eidos que explique o eidos que se quer definir (Cf. Eutífron, 10 e 9 - 11 b 5).

Esta busca por definições levou Aristóteles a afirmar que Sócrates buscava, na verdade, o universal (katholon- Cf. Met. 987 b 1- 40). Entretanto, devemos fazer as devidas reservas a esta afirmação do Estagirita, compreendendo que Aristóteles projetava sua própria filosofia em Sócrates. Ou seja: não entendamos com isto que Sócrates concebia um mundo aristotélico de seres essencialmente unos e acidentalmente múltiplos cujas substâncias primeiras eram inatingíveis, mas cujas substâncias segundas eram apreensíveis por abstração, e que, ainda, a linguagem utilizava os universais substâncias segundas e acidentes- tornando-se assim objetiva. $O$ que diferencia Sócrates de outros partidários da essência é exatamente o fato de que Sócrates não dispõe de uma ontologia definida.

Tendo isto em mente, tornam-se valiosos os comentários de Aristóteles sobre Sócrates, em especial quando o Estagirita distingue entre definições nominais e definições reais (Analíticos Posteriores, 93 b 29- 94 a 10): as primeiras seriam aquelas das quais partimos ao princípio de uma investigação e as segundas aquelas atingidas pela investigação bem sucedida, expressando, portanto, o universal: "Ao dizer que Sócrates buscava definir o universal observa Irwin (1995, p. 25)- Aristóteles supõe que Sócrates estava buscando pela definição real”. As definições reais são, para Aristóteles, a base do conhecimento científico, e, de fato, Sócrates não se cansa de afirmar que deseja atingir a ciência (episteme) dos temas morais dos quais trata. Porém, cumpre salientar que, se Sócrates busca um tal conhecimento, definições nominais são absolutamente inúteis para ele. Além disto, as exigências que Sócrates faz para aceitar uma candidata a verdadeira definição fundamentam a tese de que ele buscava realmente definições reais: 
[Sócrates] pergunta o que é F, e o que todos os efes têm em comum, não o que a palavra ' $F$ ' significa. Ele quer que the digam 'qual a própria forma pela qual as coisas pias são pias' (Eutífron $6 \mathrm{~d} 10$ ) ou algo que é igual a si mesmo em cada ação [pia]' (5 d 1). Similarmente, ele pergunta por aquele poder (dynamis) único que é comum para todos os casos de bravura (Laques 191 e 9- 192 b 8). A função explanatória que ele atribui para aquele $\mathrm{F}$ 'pelo qual' e 'graças ao qual' todos os efes são $\mathrm{F}$ é preenchida por uma essência real, não por uma essência nominal. (ibidem, p. 27)

Assim, podemos dizer que Sócrates subentende em suas discussões algo que permanece constante ao longo das mudanças, aquilo que caracteriza essencial e fundamentalmente as coisas investigadas (Vlastos, 1985, p. 104- 5). Entretanto, Sócrates não nos dá qualquer esclarecimento sobre a natureza destas entidades. Aristóteles nos informa que Sócrates não concebeu os universais como existindo separadamente das coisas sensíveis (Met. $1078 \mathrm{~b}$ 30, cf. Nakhnikian, 1980, p. 140), ao contrário de Platão, que foi, segundo Aristóteles, o primeiro "a afirmar a existência das formas" (Met., 1078 b 1112- cf. Met., 1086 b 3; Ética Nicomaquéia 1096 a 13-17).

Porém, o fato de Sócrates não determinar a natureza destas essências não o exime da responsabilidade sobre a afirmação da existência delas. Quer dizer: o fato de não possuir um discurso ontológico explícito ou definido não o torna de forma alguma menos comprometido com a tese básica e fundamental de toda e qualquer ontologia - a crença no ser, naquilo que, por sua estabilidade, caracteriza essencialmente as coisas, determinando-as necessariamente e sendo condição necessária para o verdadeiro conhecimento.

$\mathrm{Na}$ verdade, ao considerarmos a definição em Sócrates como um fundamento do elenchus de teste de definições, nos vemos forçados a the atribuir três teses que são próprias de Aristóteles. Não queremos dizer que Sócrates tenha pensado sobre estas teses ou que ele devesse se sentir obrigado a aceitá-las. Dizemos que, segundo nosso ponto de vista, sua ênfase sobre a necessidade de definições reais não pode se sustentar sem que as seguintes afirmações estejam implicadas:

(1) Toda palavra tem um sentido: esta é a primeira afirmação que Sócrates teria de aceitar para manter a coerência de sua argumentação. Se ele 
considera que as palavras não têm sentido ou nada significam, o elenchus é, por princípio, inútil, pois aí as palavras jamais poderiam nos conduzir ao conhecimento objetivo de coisa alguma.

(2) Cada coisa tem uma essência ou eidos: Sócrates manifesta esta premissa quase que explicitamente na medida em que busca o eidos ou a essência de algumas coisas. O mínimo que pode ser dito quanto a isto é que ele aposta todas suas fichas nesta possibilidade, rechaçando ou ignorando as possibilidades adversas, como, por exemplo, aquela apontada por Górgias (i.e. as coisas não têm essência). $O$ fato de não defender a realidade nem determinar a natureza destas essências não exime sua responsabilidade sobre a afirmação implícita da realidade destas mesmas essências.

(3) Há uma correspondência entre as essências das coisas e os sentidos das palavras: esta afirmação segue das demais. Se Sócrates busca o conhecimento daquelas essências, e realiza tal busca pelo elenchus de teste de definições, então tem de considerar a possibilidade de poder atingir palavras capazes de expressar estas mesmas essências.

A aceitação destas premissas caracteriza um realismo como aquele de Aristóteles e, portanto, não podemos isentar Sócrates do título de realista: se não é um realista de fato, na medida em que não falou explicitamente nem sobre ontologia nem sobre a linguagem nem sobre como se dá o conhecimento das essências, será ao menos um realista de direito, pois supõe, ao longo do diálogos socráticos, a realidade das essências e a possibilidade da linguagem comunicá-las:

Sócrates - observa Richard Robinson (1966, p. 120)- está [...] supondo algum tipo de realismo como oposto ao nominalismo, embora isto não seja algo que ele pense [explicitamente], mas apenas uma das conseqüências lógicas daquilo que ele pensa. Ele está supondo que esta forma ou essência [...] não é uma palavra na boca, ou um conceito na mente, mas algo existindo [...] independentemente do homem.

Passemos agora ao exame da concepção socrática de virtude. No Eutidemo (278 e 3- 6), Sócrates introduz uma questão da qual emergirá outro axioma básico em seu pensamento: ele indaga se todos nós em nossas 
ações desejamos agir bem (eu prattein) ou ser felizes (eudaimonein). Sócrates conclui que a felicidade é o fim último de todas as ações humanas:

Esta - diz-nos Irwin (1995, p. 33) - é também a posição do senso comum e da tradição. Homero fala de [...] deuses que desfrutam uma prosperidade segura e inabalável. Os seres humanos não podem esperar desfrutar a mesma prosperidade inabalável, já que seus sucessos são inseguros e transitórios em comparação aos deuses; entretanto, a riqueza, o poder e a honra desfrutadas por Creso e Policrates em Heródoto, e por Édipo em seus anos de rei, representam o objetivo da ambição humana, e este sucesso é descrito como [...] 'felicidade'. (Cf. Homero, Odisséia, 6. 39-46; Heródoto, I 32; III 39-43; Sófocles, OT 1186-1204)

A diferença entre Sócrates e seus contemporâneos se revelará na concepção sobre os constituintes desta felicidade e na afirmação de que a virtude infalivelmente causa o bem tanto para o virtuoso quanto para os que estão ao seu redor. Para entendermos mais sobre estas teses de Sócrates quanto à virtude, é preciso avaliar alguns passos de seus argumentos nos primeiros diálogos. Nestes, em primeiro lugar os interlocutores reconhecem ações e pessoas virtuosas, a seguir são indagadas sobre a realidade ou não desse reconhecimento para, na continuação, serem questionadas ou sobre a essência dessas virtudes ou sobre algum ponto relacionado a este. Assim, no Carmides, busca-se determinar o que é uma única virtude, pois desta forma se supõe poder responder à questão geral: "O que torna bom um homem?" Neste diálogo, a temperança é apontada como a virtude capaz de tornar uma alma virtuosa (Carmides, 156 d 6- 157 c 1). No Laques (186 c 4), a mesma questão é posta: Que tipo de educação torna um homem kalos kai agathos? Sócrates procede ao exame de diferentes virtudes que o homem deve possuir para ser bom e justo, supondo que todos querem descobrir isto, e que esta descoberta irá afetar suas idéias sobre como viver (Laques, 187 d 6- 188 c 3). A tese segundo a qual os homens desejarão seguir em suas vidas a concepção sobre o que faz bom um homem, pois desejam também sê-lo, não é nem examinada nem posta explicitamente, mas é sempre suposta por Sócrates.

Além disto, Sócrates correlaciona a ação virtuosa ao homem virtuoso. No Carmides e no Laques busca respectivamente pela propriedade que torna 
os homens temperantes e corajosos. No Eutífron (5 d 1- 2; 6 e 3- 6), a piedade é primeiro vista como uma propriedade das ações pias, mas depois a discussão se desvia para a piedade como uma propriedade de homens. Outras passagens indicam que Sócrates dá prioridade de definição para a virtude em relação ao homem e não à ação, descartando as características externas como candidatas a virtudes. No diálogo Laques, Sócrates convence o personagem Laques de que não se deve definir a coragem em relação a uma ação determinada, pois as ações corajosas devem ser compreendidas em relação à coragem das pessoas. Laques, a partir disto, observa que a coragem é "algum tipo de perseverança da alma" (Laques, 192 b 9- c 1):

Ele agora percebe que ninguém pode ser treinado para se comportar de certos modos prescritos em situações específicas descritas sem referência à coragem. Laques vê que não precisamos de homens corajosos apenas [...] na batalha; precisamos deles para perseverar numa variedade de situações que exigem perseverança. Se nós devemos treiná-los para perseverar, devemos treiná-los para reconhecer o grau de perigo e importância de enfrentá-lo; já que este reconhecimento é um estado da alma, não simplesmente uma tendência de comportamento, a coragem deve consistir em algum estado da alma.(Irwin, 1995, p. 37)

A virtude é vista por Sócrates como um estado, uma qualidade da alma. Esta concepção esbarra naquela do senso comum grego, para o qual toda qualidade ou propriedade excepcional dos seres é uma arete (excelência, virtude). Um cavalo que corre muito bem tem arete, uma árvore particularmente frutífera tem arete. Nos homens, a beleza, a força física, enfim qualquer qualidade que se destaque é vista como uma erete. Sócrates destitui tal status destas qualidades humanas, tornando a arete uma qualidade moral, uma qualidade psíquica. Em outros termos, a beleza, a força física, a habilidade de falar e as demais qualidades não são excelências por si mesmas porque não são boas por si mesmas: para Sócrates, só será boa por si mesma a excelência moral. No Carmides, ao buscar que estado da alma seria este, Sócrates supõe que a virtude deve ser boa e benéfica. $\mathrm{O}$ argumento segue aí as seguintes premissas: homens temperantes são homens bons (160 e 9); se algo torna boas as pessoas, este algo deve ser ele mesmo bom; portanto, a 
temperança é boa (160 e 13); a vergonha é tanto boa quanto má; por esta razão, a vergonha não é a temperança (161 a 11- b 2).

No Laques (192 c 4- d 5), Sócrates também pressupõe que, sendo a coragem uma virtude, ela deve ser sempre boa e benéfica. E este benefício se estende da pessoa que possui tal virtude para aos que convivem com ela. Como observa Irwin (Plato's Ethics, p. 34), a atribuição à virtude de um caráter benéfico tanto ao agente quanto aos que o rodeiam não é incontroversa entre os gregos. Um herói homérico, por exemplo, deve sempre ser o melhor e exceder aos outros (Ilíada, 11. 784) não sendo o mais cooperativo, justo ou temperante, mas sendo mais corajoso e mais eficiente na batalha (é isto que distingue Aquiles dos outros: Cf. Ilíada 1. 240-4):

Esta concepção homérica -de modo algum restrita a Homero - apresenta o agathos como a pessoa que possui qualidades necessárias para o sucesso em sua própria vida, quer estas qualidades beneficiem outras pessoas ou não, e quer estas realmente assegurem seu sucesso em vida quer não. (Irwin, 1995, p. 34)

Em outros termos, para o senso comum grego uma virtude não é sempre boa e benéfica, pois ela pode tanto beneficiar aquele que a possui, prejudicando os demais (como no caso de Ulisses que, por possuir a virtude guerreira, massacra seus adversários, os pretendentes), quanto prejudicar aquele que a possui em razão da inveja que provoca nos demais (como o sábio Palamedes, que é injusta e maliciosamente acusado por Ulisses e condenado à morte).

De acordo com o que vimos até aqui, podemos afirmar que, em seus questionamentos, Sócrates busca aquilo que supostamente permanece constante ao longo das mudanças sem oferecer qualquer esclarecimento sobre a natureza destas entidades imutáveis, o que faz com que ele se veja comprometido com os três axiomas básicos do realismo: as coisas têm essências, as palavras têm sentido, há uma correspondência entre os sentidos das palavras e as essências das coisas, o que faz de Sócrates um realista de direito. Sócrates supõe também que a virtude é um estado da alma do agente, e não um padrão de comportamento. Isto decorre da prioridade de definição da virtude em relação ao homem e não à ação. Sócrates supõe ainda que a 
virtude é sempre boa e benéfica, concepção esta de virtude estritamente moral que lhe é característica.

Estes axiomas se relacionam formando o pano de fundo do pensamento socrático: partindo da crença na realidade de entidades estáveis que determinam o real e da crença na comensurabilidade entre palavras e coisas, Sócrates se põe a buscar, através das palavras, a essência da virtude, vista como aquilo que causa a excelência no homem. Assim, Sócrates, vendo a si mesmo num mundo onde os princípios reguladores, fixos e estáveis, conduzem o fluxo ininterrupto das mudanças, sai à procura da arete moral que, sendo em si mesma fixa e estável, determina a excelência dos homens e de suas ações. 


\section{Referências Bibliográficas:}

ARISTÓTELES. Analíticos Posteriores. (trad. Tredennick \& E. S. Foster). 5 ed. Londres: Harvard University Press, 1997.

Ética Nicomaquéia. (trad. H. Rackham). 12 ed. Londres: Harvard University Press, 1994.

1996.

. Metafisica. (trad. Tredennick). 9 ed. Londres: Harvard University Press, 1994.

1996.

GUTHRIE, W. K. C. History of Philosophy. Vol 3. Cambridge: Cambridge University Press, 1969.

HOMERO. Odisséia (trad. Antônio Pinto de Carvalho). São Paulo: Abril Cultural, 1981.

IRWIN, Terence. Plato's Ethics. New York: Garland, 1995.

NAKHNIKIAN. Elenctic Definitions. Philosophy of Socrates, a Collection of Critic Essays. (org. Vlastos). Indiana: University of Znotre Dame Press, 1980

PLATÃO. Apologia. (trad. Harold North Fowler). 18 ed. Londres: Harvard University Press, 1995.

. Carmides. (trad. W. R. M. Lamb). 7 ed. Londres: Harvard University Press, 1990.

. Criton. (trad. Harold North Fowler). 18 ed. Londres: Harvard University Press, 1995.

.Eutidemo. (trad. W. R. M. Lamb). 7 ed. Londres: Harvard University Press, 1990.

. Eutifron. (trad. Harold North Fowler). 18 ed. Londres: Harvard University Press, 1995.

Górgias. (trad. W. R. M. Lamb). 13 ed. Londres: Harvard University Press, 1991.

. Hipias Menor. (trad. Alfred Croiset). Paris: Les Belles Lettres, 1949.

Íon. (trad. E. H. Warmington). Londres: Harvard University Press, 1992.

. Laques. (trad. W. R. M. Lamb). 7 ed. Londres: Harvard University Press, 1990.

. Lísias (trad. W. R. M. Lamb). 10 ed. Londres: Harvard University Press, 1991. . Mênon. (trad. Maura Iglesias). Rio de Janeiro, Editora PUC-Rio, 2001.

. Protágoras. (trad. W.R.M. Lamb). 7 ed. Londres: Harvard University Press, 1990. 
República. (trad. Maria Helena da Rocha Pereira). 2 ed. Lisboa: Calouste Gulbenkian, 1972.

RENAHAN. Pólo, Plato and Aristotle. Classical Quarterly, 45, p.68- 72, 1995.

ROBINSON, Richard. Plato's Earlier Dialectic. Oxford: Clarendon Press, 1966.

VLASTOS, Gregory. Socrates' Disavowal of Knowledge. Philosophical Quaterly, n. 35, p. 1-31, 1985.

. The Socratic Elenchus: Nethod is All. Socratic Studies (ed. Myles Burnyeat).

Cambridge, Cambridge University Press, 1994.

e-mail: aldodinucci@yahoo.com.br

Recebido: novembro/2007

Aprovado: dezembro/2007 